\title{
Radiopharmaceutical Production for PET Imaging in Poland
}

\author{
J. CHOIŃSKI* \\ Heavy Ion Laboratory, University of Warsaw, Pasteura 5a, 02-093 Warszawa, Poland
}

\begin{abstract}
At the beginning of 2000 the PET technique was not available in Poland. The structure and organization of the Radiopharmaceuticals Production and Research Centre at the Heavy Ion Laboratory, University of Warsaw is described as an example of a production department. The present status of several radiopharmaceutical production departments is presented which should give a comprehensive outlook of radiopharmaceutical production capabilities in Poland over the next few years.
\end{abstract}

DOI: $10.12693 /$ APhysPolA.127.1520

PACS: 87.56.bd, 87.57.uk, 87.57.un, 29.27.-a, 41.75.Fr, 87.56.bg, 87.56.-v

\section{Introduction}

At the beginning of 2000 the PET technique was not available in Poland. The first attempt to introduce it by obtaining a dedicated grant was made in 2001 as a result of close cooperation between the Nuclear Medicine Department of the Clinical Hospital of the Medical University of Warsaw and the Heavy Ion Laboratory of the University of Warsaw.

Soon after, the authorities of the Prof. F. Eukaszczyk Cancer Center at Bydgoszcz decided to search independently for funds. The first PET centre was finally opened in Bydgoszcz on February 26, 2003. Since then an impressive growth in the number of PET centres in Poland has taken place.

Some of these centres have their own radiopharmaceutical production department, some just PET/CT or PET/MR cameras. A map of Poland with PET centres marked is presented below (Fig. 1).

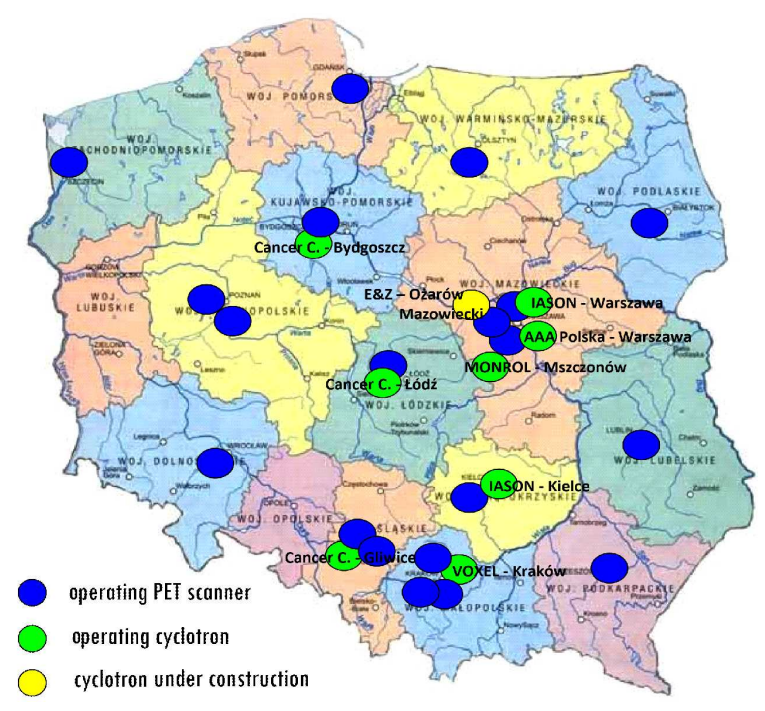

Fig. 1. The distribution of PET centres in Poland.

*e-mail: jch@slcj.uw.edu.pl
Currently, Poland hosts nine centres equipped with cyclotrons and radiopharmaceutical departments. Five of these are able to produce Fludeoxyglucose (FDG) for their own needs only. The remaining four have obtained the Polish authorities' market authorisation for FDG.

What is important that all nine centres equipped with cyclotrons are focused on producing both Fludeoxyglucose $\left({ }^{18} \mathrm{~F}\right)$ (also commonly called fluorodeoxyglucose and abbreviated [18F]FDG, 18F-FDG or FDG) and other radiopharmaceuticals containing $\mathrm{F}-18, \mathrm{C}-11, \mathrm{O}-15$ and longer lived radioisotopes like, for example, $\mathrm{Cu}-64$.

\section{The Radiopharmaceuticals Production and Research Centre at the Heavy Ion Laboratory}

The structure and organisation of the Radiopharmaceuticals Production and Research Centre (RPRC) at the Heavy Ion Laboratory, University of Warsaw is presented as an example of a typical production department [1]. The site is GMP compliant. On examining the structure, one may distinguish several functional blocks: the cyclotron vault, "hot chemistry" production laboratory, quality control department, administration, different kinds of store rooms including the archives, and technical rooms. A dual beam PETtrace 840 cyclotron made by General Electric is installed inside the cyclotron vault. The area of this room is spacious enough to host also an external beam line with a solid state target station. The parameters of the PETtrace are: proton beam current on target $\geq 80 \mu \mathrm{A}$, deuteron beam current on target $\geq 60 \mu \mathrm{A}$, length $1.25 \mathrm{~m}$, width $1.2 \mathrm{~m}$, height $1.91 \mathrm{~m}$, electricity consumption in running mode $<70 \mathrm{~kW}$, allup weight 20 tons. The cyclotron can deliver proton or deuteron beams. The appropriate internal Penning type ion sources are installed in the centre of the accelerator. The cyclotron vacuum chamber has 6 exit ports. Currently each port has its own dedicated target as follows: port no. $1-{ }^{18} \mathrm{~F}$ niobium target, port no. 2 - external solid state target station, port no. $3-{ }^{15} \mathrm{O}$ target, port no. $4-{ }^{18} \mathrm{~F}$ niobium target, port no. $5-{ }^{11} \mathrm{C}$ high pressure target, port no. $6-{ }^{11} \mathrm{C}$ normal pressure target, see the photograph below (Fig. 2).

The cyclotron vault also has a capillary feedthrough which will be useful for direct ${ }^{15} \mathrm{O}$ transfer to the nearby Nuclear Medicine Department of the Clinical Hospital. 


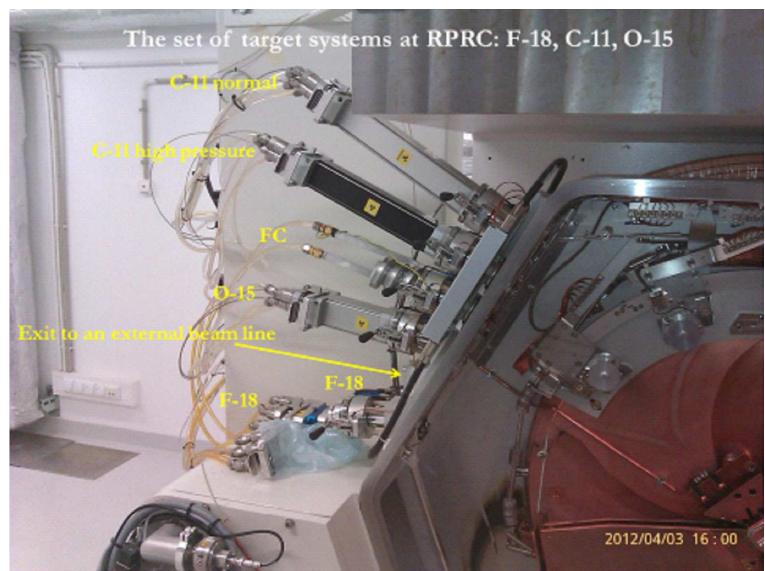

Fig. 2. A Faraday cup (FC) is attached temporally to port no. 4.

The "hot chemistry" production laboratory has two departments, one for FDG commercial production and one for so-called R\&D activity. In the FDG laboratory there are a laminar flow hood, a "hot" cell for FDG synthesizers, a "hot" cell for a dispenser unit, two General Electric FDG synthesizers, TRACERlab MX $\mathrm{FDG}_{\text {and a fully }}$ remotely controlled dispenser robot made by Comecer. In the R\&D laboratory the following equipment is installed: a laminar flow hood, a "hot" cell for ${ }^{18} \mathrm{~F}$ synthesizers, a "hot" cell for a dispenser unit, one General Electric TRACERlab FX F-N synthesizer, one Comecer fully remotely controlled dispenser robot, two additional universal "hot" cells, one water ${ }^{15} \mathrm{O}$ unit, one ${ }^{11} \mathrm{C}$ "process unit", 3 units of ${ }^{11} \mathrm{C}$ synthesizers: Synthra MeI, Synthra MeIplus and Synthra GPextent. In the Quality Control Department all tests required by the European Pharmacopeia can be performed [2]. At present the site is shared between two entities. It is leased for commercial production of FDG to Advanced Accelerator Applications Polska (AAA Polska) and the FDG known as Gluscan $\AA$ is now available for hospitals. For R\&D activity it is exploited by the HIL staff. Our first aim is to establish production of ${ }^{11} \mathrm{C}$-methionine and ${ }^{11} \mathrm{C}$-carbon acetate [3]. With the above mentioned equipment we are potentially able to produce a large number of radiopharmaceuticals. As examples: ${ }^{18} \mathrm{~F}$-Fluoromisonidazole, ${ }^{18} \mathrm{~F}$ Fluorostradiol, ${ }^{11} \mathrm{C}$-Raclopride, ${ }^{11} \mathrm{C}$-Acetate and others.

We have recently begun the production of $\mathrm{Tc}-99 \mathrm{~m}$ on the external solid state target station attached to port no. 2. Under the terms of the Agreement No. PBS1/A9/2/2012 "Alternatywne metody produkcji technetu-99m" (grant by the National Centre for Research and Development) we collaborate on this with the Institute of Nuclear Chemistry and Technology and Polatom - National Centre for Nuclear Research.

In the coming year we will carry out the work provided for in the grant PET-SKAND (by the National Centre for Research and Development) which will result in the production of scandium isotopes via the ${ }^{44} \mathrm{Ca}(\mathrm{p}, \mathrm{n}){ }^{44} \mathrm{Sc}$ and ${ }^{42} \mathrm{Ca}(\mathrm{d}, \mathrm{n}){ }^{43} \mathrm{Sc}$ reactions in the framework of a consortium of the Institute of Nuclear Chemistry and Technology, Polatom - National Centre for Nuclear Research and the Heavy Ion Laboratory, University of Warsaw.

Below there is a brief description of the remaining radiopharmaceutical centres in Poland. Below there is a brief description of the remaining radiopharmaceutical centres in Poland.

\section{The Prof. F. Łukaszczyk Cancer Center at Bydgoszcz}

The site is equipped not only with a Siemens cyclotron Eclipse $\mathrm{HP}-11 \mathrm{MeV}$ proton beam allowing production of ${ }^{18} \mathrm{~F},{ }^{11} \mathrm{C},{ }^{13} \mathrm{~N},{ }^{15} \mathrm{O}$ and ${ }^{64} \mathrm{Cu}$ but also with a Siemens $\mathrm{PET} / \mathrm{MR}$ scanner. At this oldest Polish PET centre radiopharmaceutical production is so far only for internal use, but the list of available radiopharmaceuticals is really long and contains: ${ }^{18} \mathrm{~F}-\mathrm{FDG}$ since 2002 ; ${ }^{18} \mathrm{~F}-\mathrm{FLT}$ since 2008; ${ }^{18} \mathrm{~F}$-FET since $2009 ;{ }^{11} \mathrm{C}$-acetate since 2010; ${ }^{18} \mathrm{~F}$-Sodium fluoride since $2006 ;{ }^{68} \mathrm{Ga}$-DOTATATE since 2009; water ${ }^{15} \mathrm{O}-\mathrm{H}_{2} \mathrm{O}$ since $2011 ;{ }^{11} \mathrm{C}$-Methionine since 2013; ${ }^{11} \mathrm{C}-\mathrm{Choline}$ since 2013 ; ${ }^{68} \mathrm{Ga}-\mathrm{GLP}-1$ since 2014; ${ }^{18} \mathrm{~F}$-DOPA since 2014 . They are considering production of ${ }^{68} \mathrm{Ga}-\mathrm{RGD} ;{ }^{68} \mathrm{Ga}-\mathrm{PSMA} ;{ }^{68} \mathrm{Ga}$-Annexin and ${ }^{18} \mathrm{~F}$ MFBG soon. This is the leading site in Poland.

\section{Maria Skłodowska-Curie memorial Cancer Center and Institute of Oncology, Gliwice branch}

The production part of the site is equipped with an ion beam application (IBA) dual beam (proton/deuteron) Cyclone 18/9 cyclotron. Radiopharmaceutical production is only for the centre's own needs. They produce FDG using an IBA Synthera synthesizer and Comecer Theodorico dispenser. The licensing process for FDG is in course. Installed synthesizers: Reform (BIOSCAN), Synthera (IBA), SynChrom (Raytest), Terimo (IBA). The following radiopharmaceuticals are also available: ${ }^{11} \mathrm{C}$-Choline, ${ }^{11} \mathrm{C}$-Methionine, ${ }^{11} \mathrm{C}$-Carbon acetate, ${ }^{68} \mathrm{Ga}$-DOTATATE, ${ }^{18} \mathrm{~F}$-Sodium fluoride, ${ }^{18} \mathrm{~F}$-Fluoro-LThymidine, ${ }^{18}$ F-Choline, ${ }^{18}$ F-Fluoro-Dopamine, ${ }^{124} \mathrm{I}-$ Sodium iodide, ${ }^{124}$ I-Metaiodobenzylguanidine.

\section{TNZOZ MCD Voxel at Kraków}

This GMP compliant commercial production site is equipped with a General Electric PETtrace 860 cyclotron and the following synthesizers are installed: FASTlab (GE), TRACERlab FX F-N (GE), TRACERlab FX C PRO (GE) and a TADDEO copper chloride synthesizer (Comecer). The commercial FDG known as SteriPET ${ }^{\circledR}$ is produced. Comecer "hot" cells and two Theodorico dispenser units are also installed. The site is able to produce: ${ }^{11} \mathrm{C}$-Choline (application for registration in Poland very well advanced); ${ }^{64} \mathrm{Cu}$-Copper chloride, and it is currently involved in the development of amyloid radiopharmaceuticals. In the near future ${ }^{89} \mathrm{Zr}$ is expected to be produced. 


\section{Kopernik Regional Oncology Center at Łódź}

In this centre a Siemens Eclipse cyclotron and Explora FDG synthesizer are installed, among other things. Radiopharmaceutical production is only for the centre's own needs. Apart from FDG they synthesize Sodium fluoride and ${ }^{18} \mathrm{~F}$-Choline.

\section{IASON Co. Ltd.}

Currently the company owns two premises in: the Świętokrzyskie Oncology Center at Kielce - a GMP compliant commercial production centre, and the Military Institute of Medicine at Warsaw - a research centre. Siemens Eclipse cyclotrons have been installed in both centres. The site at the Świętokrzyskie Oncology Center at Kielce delivers the well-known FDG

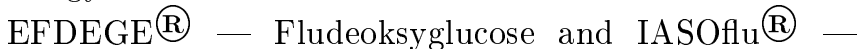
$\left.{ }^{18} \mathrm{~F}\right]$ Natriumfluoride. Independently the hospital staff of the Nuclear Medicine Department of the Swiętokrzyskie Oncology Center at Kielce is equipped with a PET/CT scanner synthesizing F-Dopa, F-Choline, FLT, FET. They plan to utilize FES and labelled tracers with Ga-68 as well.

The site at the Military Institute of Medicine at Warsaw is currently not GMP compliant and is able to produce: Choline, F-Dopa, FLT, FET and F-Miso. The centre also has an Eckert and Ziegler ${ }^{11} \mathrm{C}$ Modular-Lab Chemistry Solution installation.

\section{Monrol Poland}

The Monrol Poland centre is located at Mszczonów, roughly $60 \mathrm{~km}$ from Warsaw. This centre is built on a $2000 \mathrm{~m}^{2}$ site and is a GMP compliant commercial production unit equipped with an IBA Cyclone 18/9 cyclotron. Currently the main activity is production of FDG. The next step will be the production of other Monrol products such as ${ }^{18} \mathrm{~F}$-Sodium fluoride, Mo99/Tc99m generator, Iodine-131 Oral capsule, Iodine-131 Oral Solution, Thallium-201 Injectable Solution, Therasphere for the Polish market.

\section{Eckert \& Ziegler EURO-PET}

The Eckert \& Ziegler EURO-PET centre has been built at Ożarów Mazowiecki, not far from Warsaw. A press report states that "Eckert \& Ziegler to start production of radiopharmaceuticals in H2 2014, 18 February 2014 Karolin Riehle, of Eckert \& Ziegler, a global provider of isotope technology for medical use, has told PMR that the company plans to start the production of fludeoxyglucose (18 FDG) and other tracers for cancer imaging diagnostics at its cyclotron-based PET radiopharmaceuticals factory in the Warsaw area in the second half of 2014" [4].

\section{Conclusions}

The National Health Fund has signed contracts in 2014 with PET scanner operators for reimbursement of roughly 20000 FDG PET examinations. The present status of several existing and under construction Polish radiopharmaceutical production departments indicates that the sites are very modern with high production capabilities of FDG and other radiopharmaceuticals, greatly exceeding the present National Health Fund contracts. The presence of several GMP compliant centres with respect to about $25 \mathrm{PET} / \mathrm{CT}$ and $\mathrm{PET} / \mathrm{MR}$ scanners in Poland makes the current PET market very difficult for producers. It is an abnormal case that four producers are located in Warsaw in close vicinity. The next few years will show who is able to survive in a market where demand remains well below optimal production conditions. It is also clear that a real limitation for regular use of radiopharmaceuticals other than FDG is the lack of reimbursement from the National Health Fund. Development of new radiopharmaceuticals will be strongly correlated with the research programmes of consortia of PET producers and Nuclear Medicine Departments.

I hope that this article gives a comprehensive outlook of radiopharmaceutical production capabilities in Poland over the next few years.

\section{Acknowledgments}

I would like to thank (in alphabetical order) Dr. Andrea d'Adamico - head of the PET Center at Gliwice, Prof. Janusz Braziewicz - head of the Nuclear Medicine Department at Kielce, Hande Dilaver - the Business Development and Project Manager of Eczacibasi-Monrol, Prof. Jerzy Jastrzębski - HIL staff, Dr. Krzysztof Kilian - HIL staff, Przemysław Kozanecki - CEO of Iason Co. Ltd, Jacek Liszka - CEO of Voxel S.A., Dr. Bogdan Małkowski - head of the PET Center at Bydgoszcz, Dr. Piotr Misiewicz - head of the PET Center at Eódź, Marek Pilch-Kowalczyk - Voxel S.A., Dawid Pogoda PET Center at Gliwice and Ray Tomecki - Consultant at Monrol Poland for their support and collaboration in obtaining relevant information about their radiopharmaceutical production centres. The construction of the external solid state target station is supported by the National Centre for Research and Development.

\section{References}

[1] J. Choiński, J. Jastrzębski, K. Kilian, I. Mazur, P.J. Napiorkowski, A. Pękal, D. Szczepaniak, EPJ Web Conf. 66, 10006 (2014).

[2] K. Kilian, B. Chabecki, J. Kiec, A. Kunka, B. Panas, M. Wójcik, A. Pekal, Rep. Pract. Oncol. Radiother. 19, S22 (2014).

[3] K. Kilian, A. Pekal, W. Szkutnik, K. Pyrzyńska, Microchem. J. 115, 95 (2014).

[4] http://www.ceepharma.com/news/205336/eckertziegler-to-start-production-of-radiopharmaceuticalsin-h2-2014. 